\title{
Measurement of Capsaicinoids in Chiltepin Hot Pepper: A Comparison Study between Spectrophotometric Method and High Performance Liquid Chromatography Analysis
}

\author{
Alberto González-Zamora, ${ }^{1,2}$ Erick Sierra-Campos, ${ }^{3}$ \\ Rebeca Pérez-Morales, ${ }^{3}$ Cirilo Vázquez-Vázquez, ${ }^{1}$ Miguel A. Gallegos-Robles, ${ }^{1}$ \\ José D. López-Martínez, ${ }^{1}$ and José L. García-Hernández ${ }^{1}$ \\ ${ }^{1}$ Facultad de Agricultura y Zootecnia, Universidad Juárez del Estado de Durango, Km 35 Carretera Gómez Palacio-Tlahualilo, \\ Ejido Venecia, 35111 Gómez Palacio, DGO, Mexico \\ ${ }^{2}$ Laboratorio de Biología Evolutiva, Facultad de Ciencias Biológicas, Universidad Juárez del Estado de Durango, \\ Avenida Universidad S/N, Fraccionamiento Filadelfia, 35010 Gómez Palacio, DGO, Mexico \\ ${ }^{3}$ Facultad de Ciencias Químicas, Universidad Juárez del Estado de Durango, Avenida Artículo 123 S/N, Fraccionamiento Filadelfia, \\ 35010 Gómez Palacio, DGO, Mexico
}

Correspondence should be addressed to Erick Sierra-Campos; ericksier@gmail.com

Received 6 November 2014; Accepted 23 December 2014

Academic Editor: Maria Roca

Copyright (C) 2015 Alberto González-Zamora et al. This is an open access article distributed under the Creative Commons Attribution License, which permits unrestricted use, distribution, and reproduction in any medium, provided the original work is properly cited.

\begin{abstract}
Direct spectrophotometric determination of capsaicinoids content in Chiltepin pepper was investigated as a possible alternative to HPLC analysis. Capsaicinoids were extracted from Chiltepin in red ripe and green fruit with acetonitrile and evaluated quantitatively using the HPLC method with capsaicin and dihydrocapsaicin standards. Three samples of different treatment were analyzed for their capsaicinoids content successfully by these methods. HPLC-DAD revealed that capsaicin, dihydrocapsaicin, and nordihydrocapsaicin comprised up to $98 \%$ of total capsaicinoids detected. The absorbance of the diluted samples was read on a spectrophotometer at $215-300 \mathrm{~nm}$ and monitored at $280 \mathrm{~nm}$. We report herein the comparison between traditional UV assays and HPLC-DAD methods for the determination of the molar absorptivity coefficient of capsaicin $\left(\varepsilon_{280}=3,410\right.$ and $\left.\varepsilon_{280}=3,720 \mathrm{M}^{-1} \mathrm{~cm}^{-1}\right)$ and dihydrocapsaicin $\left(\varepsilon_{280}=4,175\right.$ and $\left.\varepsilon_{280}=4,350 \mathrm{M}^{-1} \mathrm{~cm}^{-1}\right)$, respectively. Statistical comparisons were performed using the regression analyses (ordinary linear regression and Deming regression) and Bland-Altman analysis. Comparative data for pungency was determined spectrophotometrically and by HPLC on samples ranging from 29.55 to $129 \mathrm{mg} / \mathrm{g}$ with a correlation of 0.91 . These results indicate that the two methods significantly agree. The described spectrophotometric method can be routinely used for total capsaicinoids analysis and quality control in agricultural and pharmaceutical analysis.
\end{abstract}

\section{Introduction}

Pepper (Capsicum annum L.) is an important horticultural crop of major economic significance globally, imparting flavor, aroma, and color to foods [1]. The demand for new cultivars with high levels of phytochemicals has received increasing attention for biochemists, pharmaceutical companies, plant breeders, and general public due to their health benefits.
Chiltepines (Capsicum annuum var. glabriusculum) are a wild relative of domesticated peppers that grow throughout Mexico in undisturbed sites of tropical deciduous forests and orchards, in pasture grasslands, and along roads [2, 3]. Chiltepin production in Mexico has been estimated at 50 tons/year, having great importance for subsistence farmers of the central and northern regions of the country $[3,4]$. The area where Chiltepin peppers are commercially harvested and 
recognized for the quality flavor is in the mountains in the state of Sonora, Mexico, which rarely exceed $1000 \mathrm{~m}$ altitude [5].

Montoya-Ballesteros et al. [6] observed that Chiltepin fruits in green and red stage of maturity showed differences in color, pungency, and capsaicin and dihydrocapsaicin content. These results suggest that, during fruit ripening, several biochemical, physiological, and structural modifications occur and these changes determine the attributes of fruit quality.

In relation to the importance of phytochemicals for functional aspects of pepper, the capsaicinoids are a specific class of compounds that causes the spicy sensation (pungency) of chili pepper fruit. The main capsaicinoid is capsaicin, followed by dihydrocapsaicin, nordihydrocapsaicin, homodihydrocapsaicin, and homocapsaicin. Of these compounds, capsaicin and dihydrocapsaicin account for approximately $90 \%$ of capsaicinoids in chili pepper fruit. These compounds are the two most potent capsaicinoids; their molecules differ only in the saturation of an acyl group [7] and their amount represents a quality parameter for different kind of products. In addition, capsaicin has been used traditionally for muscular pain and headache and to improve circulation and also commonly added to herbal formulations because it acts as a catalyst for other herbs and aids in their absorption. Moreover, capsaicin and other capsaicinoids have shown strong evidence that have promising potential in the fight against many types of cancer [8]. High concentrations of capsaicin occur in Chiltepin (C. annuum L. var. glabriusculum (Dunal) Heiser \& Pickersgill) [9], Bhut Jolokia (C. chinense Jacq.) [10]; and the amounts vary with genotype, fruit maturity, and conditions of cultivation [11, 12].

The fertilization regime also affects the concentrations of many secondary metabolites such as capsaicinoids and phenols $[13,14]$. Golcz et al. [15] stated that chili pepper has the greatest requirement for potassium (40\%) and nitrogen (31\%) in relation to the total amount of absorbed nutrients. Little is currently known about the effect of soil nutrients on pepper fruit pungency. Nitrogen availability may have a more direct effect on capsaicin accumulation since the synthesis of a single capsaicin molecule requires $3 \mathrm{~mol}$ of nitrogen to be formed [16]. Hence nitrogen availability may affect pepper pungency through its content in the fruit tissues. On the other hand, potassium may also affect pepper pungency given its positive effect on fruit development [17]. Previously, some studies have documented $\mathrm{N}$ and $\mathrm{K}$ effect on hot pepper [18, 19]. However, the results obtained by researchers suggest that $\mathrm{K}$ apparently does not notably interfere in capsaicin metabolization.

In the past, organoleptic tests, such as the Scoville heat test, were used to determine the pungency in peppers [20]. These methods have been replaced by analytical methods as colorimetry [21], gas chromatography [22], liquid chromatography, GC/LC-MS [23], and NMR-flow probe analysis [24]. Quantification of capsaicinoids often employs separation methods combined with ultraviolet (UV) detection [25]. Among these, the most widely used is high performance liquid chromatography (HPLC), which has become one of the most important tools in the separation and identification of capsaicinoids from raw pepper fruit extracts. In this method, a $4.6 \mathrm{~mm} \times 250 \mathrm{~mm} \mathrm{C}-18$ column (10 $\mu \mathrm{m}$ packing) is used with mobile phase consisting of a mixture of acetonitrile, dioxane, water, methanol, and perchloric acid depending on the sample concentration. For samples with more than 700 ppm, absorption UV detection at $280 \mathrm{~nm}$ is used. For samples with less than $700 \mathrm{ppm}$, fluorescence detection is employed with excitation at $288 \mathrm{~nm}$ and emission monitored at $320 \mathrm{~nm}$ [26].

At present, evaluation of capsaicinoids content in chili peppers is of great interest to plant breeders, food technologists, and nutritionists and also to assess breeding lines for genetic selection purposes or monitor levels during storage or processing. This interest has underscored the need for rapid and efficient quantification methods. HPLC methods, although more precise, are costly and require a trained operator. Simple spectrophotometric assays allow more rapid analysis $[27,28]$. However, ordinary UV-visible spectrophotometry at a single wavelength generally requires that the analyte be separated from the other absorbing constituents in the complex sample matrix before the absorbance measurements are made. Davis et al. [29] proposed a novel spectrophotometric method for the determination of capsaicinoids in habanero pepper extracts that does not require prior analyte separation. We therefore took advantage of the enhanced sensitivity of currently available spectrophotometer (absorbance measured down to a sensitivity of 0.0001 ) to develop an assay that uses capsaicinoids. The theory of the calculation of the molar absorptivity is briefly illustrated.

We address here the precision of spectrophotometer values as a reflection of total amount of capsaicin and dihydrocapsaicin, which represents the majority of capsaicinoids content in chili peppers, and we compared values obtained with simple spectrophotometer readings with the cumulative amounts of individual capsaicinoids identified through HPLC analysis. The presence of correlation between the two methods is disclosed and discussed.

\section{Experimental}

2.1. Reagents. All the reagents, standards (capsaicin >95\%; dihydrocapsaicin about $90 \%$ from Capsicum sp.), and solvents used were of high degree of purity or HPLC grade and were purchased from Sigma-Aldrich (St. Louis, MO, USA).

2.2. Plant Material and Growth Conditions. A sample of seeds of three different semidomesticated cultivars (named here $\mathrm{Ch} 1, \mathrm{Ch} 2$, and $\mathrm{Ch} 3$ ) was obtained from the semiarid regions of the state of Sonora, in Northwest Mexico. These three cultivars are not significantly different morphologically and grow in different regions of the Sonoran Desert where people harvest the fruits and aid in seed dispersal. The three cultivars were cultivated in an experimental area within a rural land of the municipality of Francisco I. Madero, Coahuila, Mexico $\left(25^{\circ} 46^{\prime} 31^{\prime \prime} \mathrm{N} ; 103^{\circ} 16^{\prime} 23^{\prime \prime} \mathrm{W}\right)$. In this region, the average altitude is $1105 \mathrm{~m}$, the climate is predominantly semidry, the average annual temperature is $22^{\circ} \mathrm{C}$, with maximum temperatures of $45^{\circ} \mathrm{C}$ in summer and minimum of $4^{\circ} \mathrm{C}$ in winter, and the average annual rainfall is less than $400 \mathrm{~mm}$ [30]. 
According to technical recommendations by Molina et al. [31], seeds were treated before germination as follows: they were soaked in water without chlorine for about $72 \mathrm{~h}$ and afterward they were germinated in greenhouse conditions at $25^{\circ} \mathrm{C}$ in Jan. 2013. Seeds were placed within polystyrene trays of 200 cavities filled with a mixture of peat moss and vermiculite as substrate; one seed per cavity was placed at a depth of $5 \mathrm{~mm}$ from the base and sprayed with water. The trays were placed under shade at $22^{\circ} \mathrm{C}$ and covered with black plastic. Irrigation was performed once a week until the day of transplant, which was performed 82 days after the date of germination. The transplant was directly from the trays to the field, when seedlings had an approximate minimum height of $20 \mathrm{~cm}$, in Apr. 2013. Distance between plants and rows was $1 \mathrm{~m}$. Vermicompost was used as fertilizer in an amount of $4.5 \mathrm{t} \mathrm{ha}^{-1}$. The irrigation drip was provided every 20 days at field capacity. The fruit was harvested GM in July 2013, 77 days after to transplant and then RR 87 days after transplant.

2.3. Collection of Fruits from Plant Materials. Samples were collected at two stages of maturity, green mature (fresh) and red ripening, and then dried using a cabinet-type convective dryer at $65^{\circ} \mathrm{C}$ by $24 \mathrm{~h}$ and triturated.

2.4. Capsaicinoids Extraction. The capsaicinoids were extracted from the dried fruits following the methods proposed by Al Othman et al. [32] and Parrish [33] slightly modified as follows: briefly, the dried fruits were powdered and $1 \mathrm{~g}$ was treated with $10 \mathrm{~mL}$ of acetonitrile at $65^{\circ} \mathrm{C}$ along 20 min under sonication, with a working frequency of $35 \mathrm{kHz}$. The extracts were evaporated to dryness at $60^{\circ} \mathrm{C}$, resuspended in $0.5 \mathrm{~mL}$ of acetonitrile, and filtrated through $0.45 \mu \mathrm{m}$ cellulose acetate membrane filter (GVS Filter Technology, Indianapolis, IN, USA). Samples were stored at $-20^{\circ} \mathrm{C}$ until they were analyzed.

2.5. Capsaicinoids Analysis by HPLC-DAD. Chromatography conditions were based on the validated method reported previously [9]. The analyses of capsaicinoids were performed by HPLC-DAD (Agilent 1200, Agilent Technologies Palo Alto, CA, USA) employing a reversed phase column Kromasil Eternity-5-C18 $(4.6 \times 150 \mathrm{~mm})$ with Precolumn (SUPELCO Analytical, Sigma-Aldrich) at $25^{\circ} \mathrm{C}$. Elution was performed with an isocratic mixture of water : acetonitrile $50: 50$. Detection was set at 202, 222, and $280 \mathrm{~nm}$. Injection volume was $20 \mu \mathrm{L}$. All peaks related to capsaicinoids were eluted in about $15 \mathrm{~min}$. Quantitative analysis was performed following the external standard method. Calibration curves were built by injecting by triplicate of ten increasing concentrations of standard. Nordihydrocapsaicin was quantified using the calibration curve of dihydrocapsaicin, since it was not commercially available.

2.6. Spectrophotometric Method. The absorbance of the unknown samples solutions was read using one cm quartz cell in a UV-Vis spectrophotometer (HACH DR-5000).

Preparation of Standard Stock Solution. Pure capsaicin or dihydrocapsaicin was weighed and dissolved in acetonitrile up to $2.0 \mathrm{~mL}$ to get the stock solution of $2 \mathrm{mg} / \mathrm{mL}$. The solution was then filtered with $0.45 \mu \mathrm{m}$ syringe filter. The stock solution of capsaicin or dihydrocapsaicin was diluted as required. Calibrate daily with at least six working standards over the range of 10 to $200 \mathrm{mg} / \mathrm{L}$ for each standard. These dilutions were scanned in the UV-Vis spectrometer and $\lambda_{\max }$ of capsaicin was selected as wavelength of detection. The instrument was set at $280 \mathrm{~nm}$. The capsaicinoids content in the unknown extract solutions was calculated based on the absorbance values of known standard solutions.

2.7. Pungency. Capsaicinoid content was converted to Scoville heat unit (SHU) by multiplying the concentration of capsaicinoid in dry weight of pepper in parts per million ( $\mathrm{ppm}$ ) by the coefficient of the heat value for each compound, 9.3 for nordihydrocapsaicin and 16.1 for both capsaicin and dihydrocapsaicin for HPLC [22]:

$$
\begin{aligned}
& \text { Total SHU } \\
& \begin{aligned}
= & {[\mathrm{C}(\mathrm{ppm})+\mathrm{DHC}(\mathrm{ppm})] \times 16.1 } \\
& +[\mathrm{n}-\mathrm{DHC}(\mathrm{ppm}) \times 9.3]
\end{aligned}
\end{aligned}
$$

Then the conversion to SHU from total capsaicinoids content obtained by spectrometric method in dry weight of pepper was done by multiplying the coefficient corresponding to the heat value for capsaicin, which is $1.6 \times 10^{7}$ [34]

2.8. Statistical Analysis. Experimental data are shown as the mean \pm standard error of assay run in triplicate for capsaicinoids content. The statistical test was an ANOVA, for which we used SPSS version 15.0 for Windows. The means of treatments were compared with Tukey's multiple range test $(P \leq$ $0.05)$. Linear correlation analysis for total capsaicinoids using HPLC and spectrophotometric method was conducted using Deming regression analysis with Bland-Altman plots. All statistical calculations of correlation were performed using Medcalc version 12.3 (Mariakerke, Belgium).

\section{Results and Discussion}

3.1. Calculation of the Molar Absorptivity Coefficient by HPLC and Spectrometric Method. Few attempts have been made to calculate absorption coefficient for capsaicinoids. The majority of capsaicinoids exhibit absorption in the UV region of the spectrum, between 200 and $350 \mathrm{~nm}$. Because these obey the Beer-Lambert law (absorbance is linearly proportional to the concentration), absorbance measurement can be used to quantify the concentration of a pure (standard) capsaicinoid or to estimate the total capsaicinoid concentration in a mixture or extract of capsaicinoids in a sample. Standards of capsaicinoids (capsaicin and dihydrocapsaicin) commercially purchased were dissolved in acetonitrile and the spectrum was scanned in order to evaluate their fine structure (Figures 1(a) and 1(b)). Using the absorbance measured at its maximum wavelength $(280 \mathrm{~nm})$ and taking into consideration the dilution factor, purity degree, and molecular mass (capsaicin $305.41 \mathrm{~g} / \mathrm{mol}$; dihydrocapsaicin $307.43 \mathrm{~g} / \mathrm{mol}$ ), the 


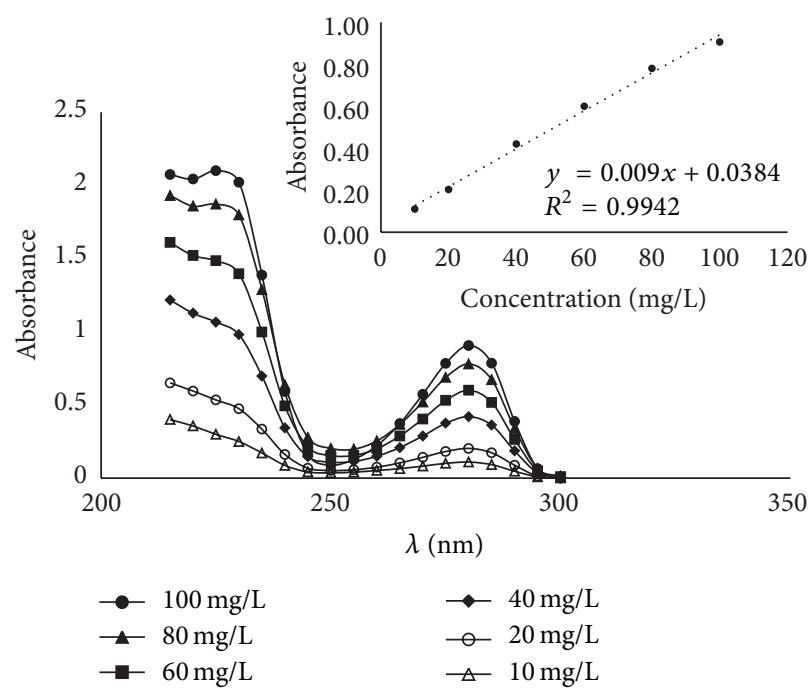

(a)

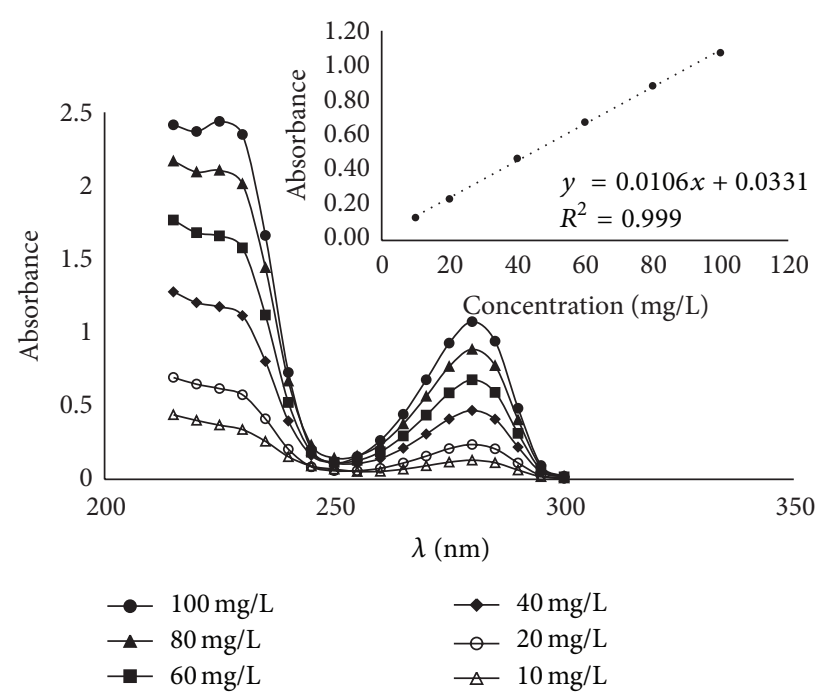

(b)

FIGURE 1: UV-Vis spectra of different concentrations of capsaicin (a) and dihydrocapsaicin (b). Insert, calibration curve of each capsaicinoid. The regression line equations for capsaicin and dihydrocapsaicin were $(y=0.0097 x+0.03)$ and $(y=0.0106 x+0.031)$, respectively.

molar absorption of each standard capsaicinoid was calculated, using the following well-known equation:

$$
A=\varepsilon \cdot b \cdot c
$$

where $A$ is absorbance (dimensionless), $b$ is the path length through the sample in $\mathrm{cm}, \varepsilon$ is the molar absorbance coefficient in liter $\mathrm{mol}^{-1}$, and $c$ is the molar concentration in mol liter $^{-1}$.

Regarding linearity, spectrophotometric test exhibited a linear response between $10 \mu \mathrm{g} / \mathrm{mL}$ and $100 \mu \mathrm{g} / \mathrm{mL}$ and the representative equation of analysis was $y=0.009 x+0.038$; a collection of 3 calibration curves presented a correlation coefficient 0.994 for capsaicin and $y=0.01 x+0.033$, with a correlation coefficient of 0.99 for dihydrocapsaicin (inset, Figures 1(a) and 1(b)). The molar absorptivity coefficient of capsaicin is $\left(\varepsilon_{280}=3410 \mathrm{M}^{-1} \mathrm{~cm}^{-1}\right)$ and of dihydrocapsaicin is $\left(\varepsilon_{280}=4175 \mathrm{M}^{-1} \mathrm{~cm}^{-1}\right)$. LOD and LOQ were found to be 0.070 and $0.213 \mu \mathrm{g} \cdot \mathrm{mL}$ for capsaicin, while LOD and LOQ for dihydrocapsaicin were 0.161 and $0.49 \mu \mathrm{g} \cdot \mathrm{mL}$, respectively. The results indicated excellent recoveries ranging from 98.5 to $99.3 \%$ and 99 to $101.6 \%$ for capsaicin and dihydrocapsaicin, respectively, and reliability of the method.

The same experimental conditions were applied to all capsaicinoids obtained by the HPLC-DAD method. LambertBeer's law is valid for a DAD detector, which is a spectrophotometer submitted to a dynamic and continuous HPLC flow, operating on chromatographically separated molecules. As proposed by Locatelli et al. [35], (3) can be used when $\varepsilon$ is calculated as the slope of a straight-line regression built using the injected mass and the corresponding areas recorded by the DAD detector as follows:

$$
\text { Area }=\varepsilon \cdot \frac{0.06 \cdot b \cdot m_{0}}{F \cdot \mathrm{MW}} .
$$

Area is expressed in ( $\mu \mathrm{AUs}), \mathrm{MW}\left(\mathrm{g} \mathrm{mol}^{-1}\right)$ is the molecular weight, and $m_{0}$ (ng) is the injected mass. The application of (3) at an HPLC flow of $1.0 \mathrm{~mL} \mathrm{~min}^{-1}$ yielded for capsaicin (C) $\varepsilon_{280}=3,720 \pm 36 \mathrm{M}^{-1} \mathrm{~cm}^{-1}$ and for dihydrocapsaicin (DHC) $\varepsilon_{280}=4,350 \pm 30 \mathrm{M}^{-1} \mathrm{~cm}^{-1}$. The ratio between $\mathrm{C}$ and DHC $\varepsilon$ values, at $280 \mathrm{~nm}$, was $\varepsilon$ C, $280 / \varepsilon \mathrm{DHC}, 280=0.855$. Similarly, the lower limit of quantitation (LOQ) was determined by injecting a standard at a concentration that resulted in an $S / N$ ratio of 10 . The determination of the limit of detection (LOD) was analysed on the basis of $\mathrm{S} / \mathrm{N}$ ratio of 3 . The LOD and LOQ for this method were $0.0038 \mu \mathrm{g} \cdot \mathrm{mL}$ and $0.0116 \mu \mathrm{g} \cdot \mathrm{mL}$ for capsaicin, respectively. Relative standard deviation (RSD) of the within-day and day to day was $0.02-0.05 \%$ and $0.08-$ $0.1 \%$ for capsaicin and dihydrocapsaicin, respectively.

3.2. Assessment of the Accumulation of Capsaicinoids at Two Ripening Stages in Chiltepin Fruits. The pungent metabolites in the fruits of Capsicum species are called capsaicinoids, which are a group of 12 or more alkaloids with a structure of vanillylamide of branched fatty acids with 9-11 carbons [36], but capsaicin and dihydrocapsaicin are responsible for more than $90 \%$ of the pungency [37]. The capsaicin content in chili peppers is variable and ranges from 0.1 to $1 \%$ of the fruit weight approximately, but the amount varies depending on the temperature at which the plant is grown, the age of the fruit, the light, and soil composition [32]. The addition of mineral supplements to the pepper crops causes an increase in the capsaicinoid content of the fruit [38] and this nitrogen supply is essential for the synthesis of such compound [39]. However, due to adverse effects of chemical fertilizers, interest has been stimulated for the use of organic manures. Vermicompost is produced by biodegradation of organic material through interactions between earthworms and microorganisms [40]. 
Chiltepin has high phenotypic plasticity, shown by the variation of traits such as leaf morphology, fruit shape, seed germination pattern, or resistance to pathogens [2]. In Mexico, it can be found from the Yucatan peninsula and the Gulf of Mexico, where it grows in deep soils with dense evergreen vegetation, to xeric regions in the Sonoran desert or the central plateau, where it is commonly associated with nurse trees [41]. Harvesting the fruits of Chiltepin is still a common practice in central and northern Mexico and the total harvest has been estimated to be 50 metric tons per year [3]. However, environmental degradation, grazing, and harvesting have severely impacted many native populations of this species [41].

In the present work we have determined the content of capsaicin, dihydrocapsaicin, and nordihydrocapsaicin by HPLC-DAD to compare the total capsaicinoids level obtained by spectrometric method to study the influence of maturity stage and vermicompost on quality in capsaicinoids composition in Chiltepin fruits.

Chiltepin chili samples showed a high concentration of capsaicinoids in the two stages of maturity GM and RR (Table 1). Nordihydrocapsaicin, capsaicin, and dihydrocapsaicin were observed in the fruit of all samples. However, the amount of nordihydrocapsaicin was lower (5 to 9\%) than capsaicin (30 to 59\%) and dihydrocapsaicin (32 to 63\%) relative to the total of capsaicinoids. Homocapsaicin and homodihydrocapsaicin were only present in some samples and in small percentages (from less than $1 \%$ to $4 \%$ ) compared to total capsaicinoids content. HPLC revealed that capsaicin and dihydrocapsaicin comprised up to $93 \%$ of total capsaicinoids content detected in the studied samples. Capsaicin content of the control samples without vermicompost ranged from $1.63 \pm 0.04$ to $5.41 \pm 0.29 \mathrm{mg} / \mathrm{g}$ dry weight in red ripe fruit. Levels of capsaicin assessed of samples with vermicompost varied from $3.23 \pm 0.18$ to $6.43 \pm 0.22 \mathrm{mg} / \mathrm{g}$ dry weight in red ripe fruit. Capsaicin content was higher in green mature fruit than red ripe fruit (see Table 1). The content ranged from $23.78 \pm 0.87$ to $40.14 \pm 0.25 \mathrm{mg} / \mathrm{g}$ dry weight in green mature samples without vermicompost (control) and $42.02 \pm 1.93$ to $56.68 \pm$ $1.49 \mathrm{mg} / \mathrm{g}$ dry weight in green mature samples treated with vermicompost. In most cases, capsaicin levels were greater than dihydrocapsaicin, except for Chl RR-Cr, Chl Gm-Cr, and $\mathrm{Ch} 2 \mathrm{Gm}-\mathrm{Cr}$. Ch2 GM-Vc was the cultivar showing the highest values of total capsaicinoids $\left(107.01 \pm 1.55 \mathrm{mg} \mathrm{g}^{-1}\right)$ and therefore the highest value of pungency. Lowest values of capsaicinoids were observed in Chl to GM $(71.12 \pm 2.51 \mathrm{mg}$ $\left.\mathrm{g}^{-1}\right)$ and Ch3 to RR $\left(30.70 \pm 1.07 \mathrm{mg} \mathrm{g}^{-1}\right)$, except for the case of dihydrocapsaicin where Chl to GM $(29.49 \pm 1.32 \mathrm{mg}$ $\left.\mathrm{g}^{-1}\right)$ and Ch3 to RR $\left(11.96 \pm 0.26 \mathrm{mg} \mathrm{g}^{-1}\right)$ showed the lowest values. The difference between the lowest and highest value is 3.5 -fold.

The direct-absorbance measurement of total capsaicinoids levels could have interferences from other compounds present in the pepper fruit extracts. Therefore, after the validation by HPLC, we evaluated the spectrophotometric method applied for total capsaicinoids in Chiltepin fruit samples. Figure 2 shows the typical spectrum of Chl RR-Cr and Ch1 RR-Cr-C+DHC complex overlain spectra and the results

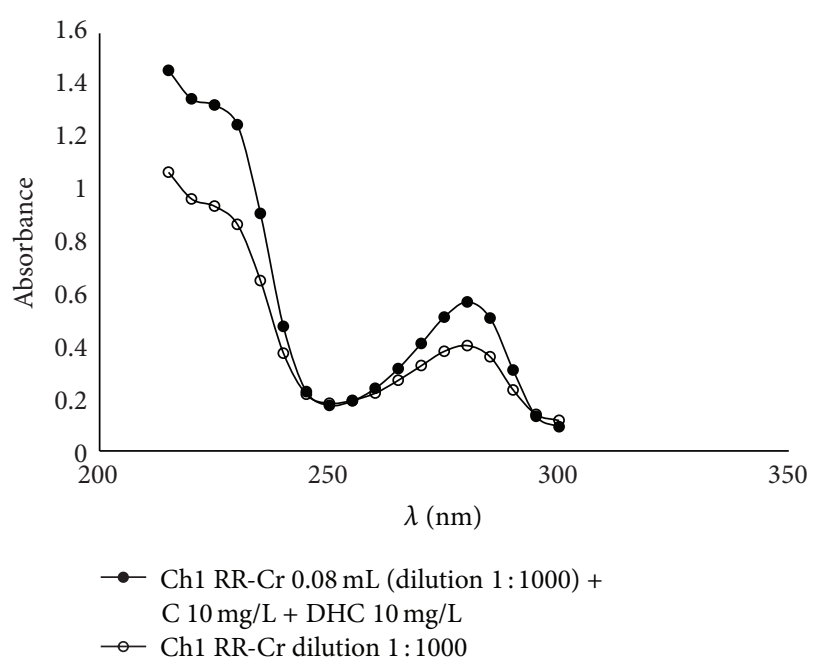

FIGURE 2: UV absorption spectrum of dry Chiltepin fruit extract without standards (white circle) and with standards (capsaicin " $\mathrm{C}$ " and dihydrocapsaicin "DHC"; black circle).

obtained are shown in Table 1 in accordance with the HPLCDAD analysis. Recoveries obtained for the standards did not differ significantly from $100 \%$ showing that there was no interference from other common compounds present in extract and thus indicating accuracy and reliability of the method.

The capsaicinoids content, as determined by the spectrophotometric method, was generally higher in GM ripe fruit than red fruit (see Table 1). The content varied from $20.18-97.73 \mathrm{mg} / \mathrm{g}$ for RR samples to $59.47-118.93 \mathrm{mg} / \mathrm{g}$ for GM stage. Samples showed a considerable percentage of decrease in capsaicinoids levels depending on the stage of maturation from GM to RR. Ch3 was the cultivar that showed the greatest variation in the capsaicinoids content. The values of these metabolites in RR stage decreased by $62.8 \%, 51.2 \%$, and $45.6 \%$ for nordihydrocapsaicin, capsaicin, and dihydrocapsaicin, respectively. This produces fruits with an average 50\% less pungency in the RR stage regarding GM. For Ch1 and Ch2 pungency levels are 20\% lower in RR than in GM.

\subsection{Effects of Vermicompost Fertilization on Capsaicinoids} Content in Chiltepin Pepper Fruit. Vermicompost and compost can meet the nutrient demand of crop and significantly reduce the excessive use of chemical fertilizers in agriculture [42], and, for vermicompost in particular, increase soil fertility without polluting the soil, as well as the quantity and quality of harvested product [43]. According to Ramesh et al. [44], organic production is an alternative for consumers who prefer food free of pesticides and synthetic risk-free fertilizers, with high nutritional value, and growing media promotes the development and productivity of pepper $[45,46]$.

Under the studied conditions, the fruit in the vermicompost treatment experienced very high capsaicinoids accumulation in different samples. The results presented in Table 1 clearly demonstrated that vermicompost had a significant effect on the capsaicin content of Chiltepin peppers; this 


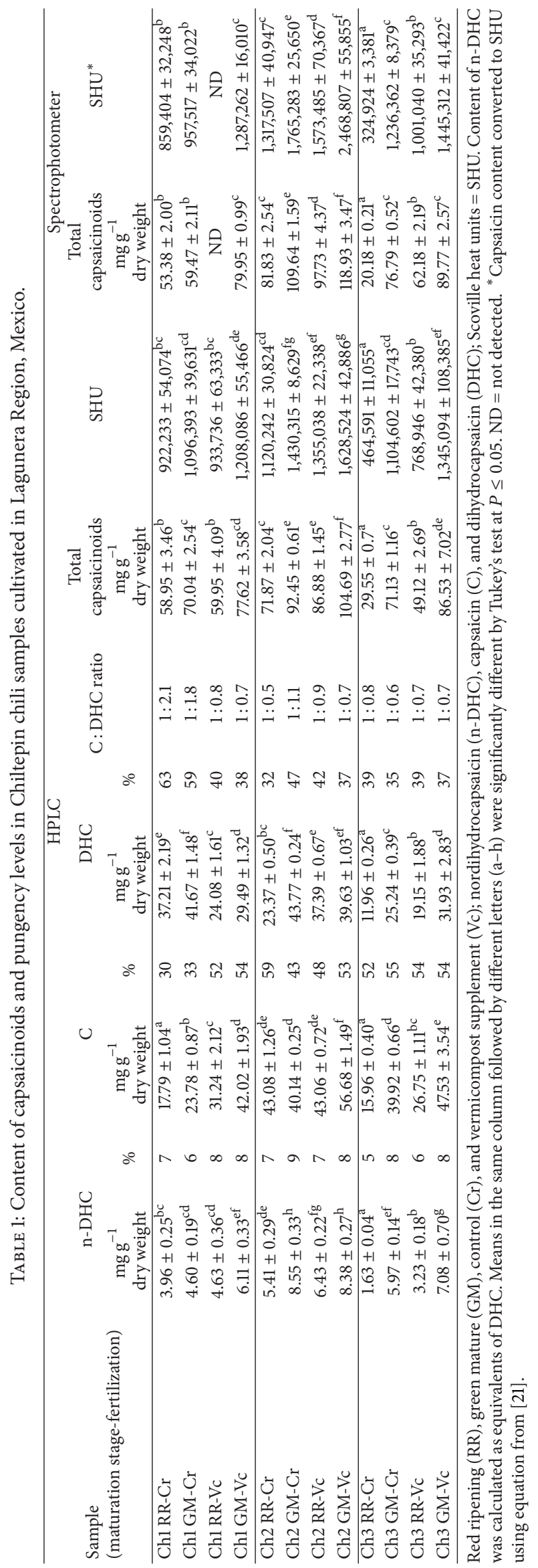




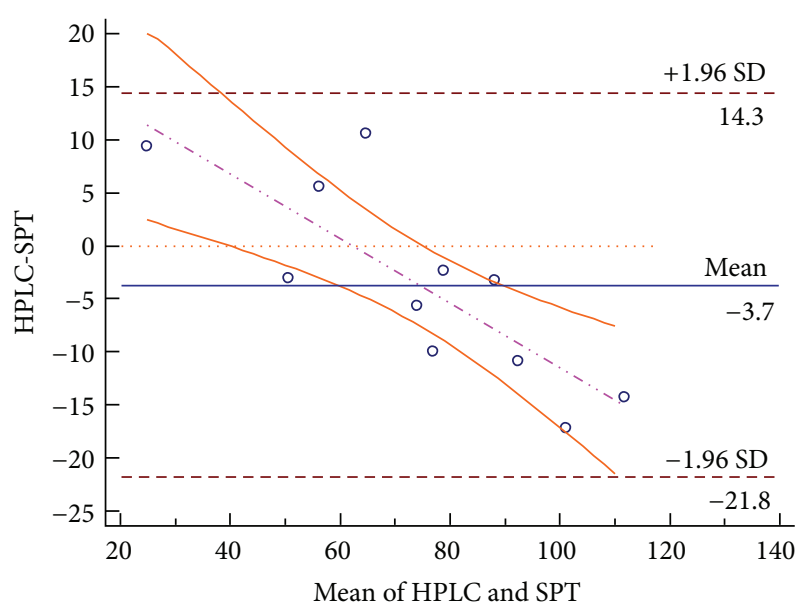

(a)

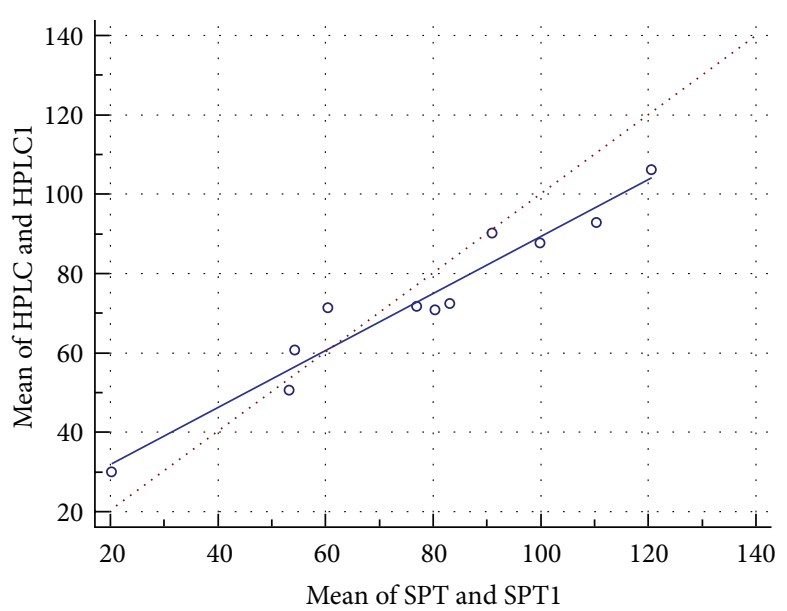

(b)

FIGURE 3: Bland-Altman plot for total capsaicinoids in Chiltepin fruit extracts. (a) The solid line represents the mean difference in measured capsaicinoids concentrations between methods, and the dashed lines are \pm 2 SD. Mean difference: -3.7 , standard deviation: 1.96 , and $95 \%$ limit of agreement: -21.8 to 14.3. (b) By Deming regression of the scatter plot, the slope is 0.716 ; the intercept, 17.59; and the correlation coefficient $(r)=0.88$. These results indicate a fair degree of correlation between HPLC and spectrometric (SPT) values.

treatment showed about two times more capsaicin than control treatment. Also, dihydrocapsaicin concentration was affected significantly by the vermicompost treatment, but considerable variability was observed for this capsaicinoid in the different samples. The accumulation of capsaicinoids depends on synthesis and degradation. Capsaicinoids synthesis generally begins with one week after fruit set and continues as placental tissues develop. The compounds reach maximum levels approximately 40-50 days after fruit set [47, 48]. Upon maturation, capsaicinoids levels in most cultivars show a noticeable variable rate of decline associated with an increase in the activity of peroxidase enzymes in ripe fruit $[49,50]$. Our results have also indicated that capsaicin levels in GM stage were higher than in RR stage, and vermicompost fertilization does not alter this behavior. This is apparently the first report in Chiltepin pepper of fertilization treatment affecting the metabolism of capsaicinoids responsible for pungency. We can deduce that, in RR stage, the peroxidases may be involved in the degradation of capsaicinoids.

3.4. Spectrophotometer Compared to HPLC. It is assumed that spectrophotometric estimation of the capsaicinoids is inaccurate because of interference of other compounds present in the extract. However, in a previous study, high levels of agreement were found between colorimetric and chromatographic techniques [21]. Although HPLC measurements are in general more precise and reproducible than spectrophotometric methods, these techniques can be an alternative to determine the total capsaicinoids, in spite of the fact that their efficacy is limited, perhaps partly because of carotenoids and chlorophylls. Thus, such testing requires standardized and reproducible techniques.

The agreement between quantification by HPLC-DAD and spectrophotometric method was evaluated by the graphical investigation of difference-plots [51] and by Deming regression analysis [41]. Difference-plots are useful tools to display differences between methods, but they do not provide statistical tools for inference of the differences. The Deming regression analysis is suitable if measurement errors are proportional and the procedure accounts for errors in both methods [3]. In this case, samples were not analyzed in replicates and equal variance between the two methods was assumed. Medcalc was used for Deming regression analysis and difference-plots.

In difference-plot (Figure 3(a)) and Deming regressions (Figure 3(b)) for capsaicinoids in Chiltepin fruit extracts, the differences between the two methods (HPLC values subtracted from spectrophotometer values) were plotted against the mean concentrations shown by the two methods (Figure 3). The mean differences are shown (solid lines), as are the limits of agreement (broken lines), corresponding to mean \pm 2 SD. Concentrations quantified by HPLC-DAD and spectrophotometer are plotted against each other (dots) for total capsaicinoids (Figure 3(a)) and the Deming regression (capsaicinoids: $y=17.59+0.716 x$ ) is indicated (unbroken lines), as the identity lines (broken lines).

When comparing simple spectrophotometric and HPLC quantification methods, identical trends among varieties after the performance of means separation were revelated between total capsaicinoids concentrations (spectrophotometer) and total capsaicinoids concentration (HPLC) (Figure 4). A high linear relationship $(r=0.913 ; P<0.001)$ was observed after correlation analyses. Differences between spectrometric measurements and HPLC analyses in total capsaicinoids content among different samples have shown slightly higher 2 to $26 \%$ difference ranging 2-24 mg/ $\mathrm{kg}^{-1}$ dry wt (Table 1).

Total capsaicinoids quantified by HPLC correlated closely with spectrophotometer values. The correlation coefficient was $0.91(P<0.001)$ for capsaicinoids in Chiltepin pepper fruit, indicating a strong positive association between these 


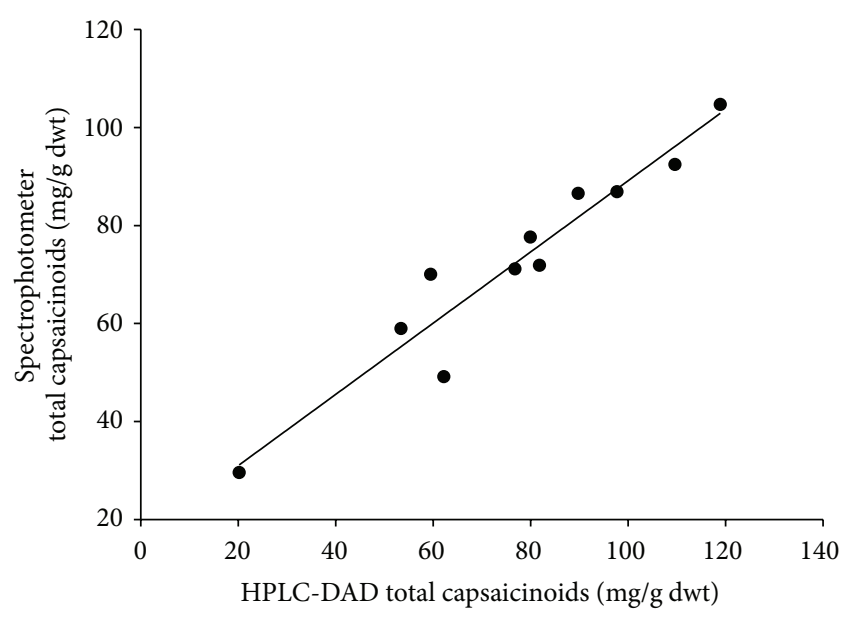

FIGURE 4: Correlation between cumulative capsaicinoids of Chiltepin acetonitrile extract separated by HPLC and total capsaicinoids by spectrophotometer $(r=0.91), n=11$.

values. The simple spectrophotometric procedure proved to be a valid, efficient, and cost-effective method for the quantification of total capsaicinoids in these conditions, which in fact adequately represent total capsaicinoids content in hot chili pepper extracts.

\section{Conclusion}

This study describes a spectrophotometric method for the precise determination of total capsaicinoids in pepper fruit samples and yields a close estimation, but it is not as accurate as HPLC-DAD. Further investigation is needed to understand the origin of these analytical errors. The method is an effective mean for quality control and is a viable alternative to the existing analytical methods for routine analyses, allowing a rapid and accessible quantitation of capsaicinoids in fruits samples without any time-consuming sample separation. In addition, our results indicate that, in contrast to other studies where capsaicin content was generally higher in ripe fruit than green fruit, Chiltepin red ripening fruits showed lower levels of capsaicin and dihydrocapsaicin than green mature fruits in all samples. Vermicompost treatment affected capsaicin and dihydrocapsaicin levels and favors the accumulation of capsaicin.

\section{Conflict of Interests}

The authors declare that there is no conflict of interests regarding the publication of this paper.

\section{Acknowledgments}

This study was possible with the support of research Grant no. 2009-134382 from Consejo Nacional de Ciencia y Tecnología in Mexico (CB-SEP-CONACYT). The first author was supported by a Doctoral Research Fellowship no. 327844, CVU no. 164727 (CONACYT). Erick Sierra-Campos acknowledged SNI (CONACYT) for the stipend received. The authors are very thankful to Mónica A. Valdez-Solana, Jaime A. de LiraSánchez, Jorge A. Sosa-Gutierrez, and Eliab M. GonzálezOlvera for helpful discussions and critical reading of this paper and to Raymundo Montelongo, Miguel de la Cruz, and J. Guadalupe Luna for agronomic support and work in the experimental field.

\section{References}

[1] N. Caporaso, A. Paduano, G. Nicoletti, and R. Sacchi, "Capsaicinoids, antioxidant activity, and volatile compounds in olive oil flavored with dried chili pepper (Capsicum annuum)," European Journal of Lipid Science and Technology, vol. 115, no. 12, pp. 14341442, 2013.

[2] S. Hernández-Verdugo, R. Luna-Reyes, and K. Oyama, "Genetic structure and differentiation of wild and domesticated populations of Capsicum annuum (Solanaceae) from Mexico," Plant Systematics and Evolution, vol. 226, no. 3-4, pp. 129-142, 2001.

[3] E. J. Votava, G. P. Nabhan, and P. W. Bosland, "Genetic diversity and similarity revealed via molecular analysis among and within an in situ population and ex situ accessions of chiltepín (Capsicum annuum var. glabriusculum)," Conservation Genetics, vol. 3, no. 2, pp. 123-129, 2002.

[4] J. G. Almaza, R. K. Maiti, P. R. Foroughbakhch et al., "Bromatología del chile piquín (Capsicum annuum $\mathrm{L}$. var. aviculare (Dierb.) D \& E)," in Resúmenes 15th Congreso Mexicano de Botánica, Querétaro, Mexico, 2001.

[5] W. G. D’Arcy and W. H. Eshbaugh, "New world peppers (Capsicum-Solanaceae) north of Colombia: a resume," Baileya, vol. 19, pp. 93-105, 1974.

[6] L. C. Montoya-Ballesteros, A. Gardea-Béjar, G. M. AyalaChávez, Y. Y. Martínez-Núñez, and L. E. Robles-Ozuna, "Capsaicinoides y color en chiltepín (Capsicum annuum var. aviculare). processing effect on sauces and pickles," Revista Mexicana de Ingenieria Química, vol. 9, no. 2, pp. 197-207, 2010.

[7] M. A. Bernal, A. A. Calderón, M. A. Pedreño, R. Muñoz, A. R. Barceló, and F. Merino De Cáceres, "Capsaicin oxidation by peroxidase from Capsicum annuum (var. annuum) fruits," Journal of Agricultural and Food Chemistry, vol. 41, no. 7, pp. 1041-1044, 1993.

[8] X.-F. Huang, J.-Y. Xue, A.-Q. Jiang, and H.-L. Zhu, "Capsaicin and its analogues: structure-activity relationship study," Current Medicinal Chemistry, vol. 20, no. 21, pp. 2661-2672, 2013.

[9] A. González-Zamora, E. Sierra-Campos, J. G. Luna-Ortega, R. Pérez-Morales, J. C. R. Ortiz, and J. L. García-Hernández, "Characterization of different Capsicum varieties by evaluation of their capsaicinoids content by high performance liquid chromatography, determination of pungency and effect of high temperature," Molecules, vol. 18, no. 11, pp. 13471-13486, 2013.

[10] Y. Liu and M. G. Nair, "Capsaicinoids in the hottest pepper Bhut Jolokia and its antioxidant and antiinflammatory activities," Natural Product Communications, vol. 5, no. 1, pp. 91-94, 2010.

[11] Y. Zewdie and P. W. Bosland, "Evaluation of genotype, environment, and genotype-by-environment interaction for capsaicinoids in Capsicum annuum L," Euphytica, vol. 111, no. 3, pp. 185190, 2000.

[12] G. F. Barbero, A. G. Ruiz, A. Liazid, M. Palma, J. C. Vera, and C. G. Barroso, "Evolution of total and individual capsaicinoids in peppers during ripening of the Cayenne pepper plant (Capsicum annuum L.)," Food Chemistry, vol. 153, pp. 200-206, 2014. 
[13] J. P. Bryant, T. P. Clausen, P. B. Reichardt, M. C. McCarthy, and R. A. Werner, "Effect of nitrogen fertilization upon the secondary chemistry and nutritional value of quaking aspen (Populus tremuloides Michx.) leaves for the large aspen tortrix (Choristoneura conflictana (Walker))," Oecologia, vol. 73, no. 4, pp. 513-517, 1987.

[14] P. Gremigni, J. Hamblin, D. Harris, and W. A. Cowling, "The interaction of phosphorus and potassium with seed alkaloid concentrations, yield and mineral content in narrow-leafed lupin (Lupinus angustifolius L.)," Plant and Soil, vol. 253, no. 2, pp. 413-427, 2003.

[15] A. Golcz, P. Kujawski, and B. Markiewicz, "Yielding of red pepper (Capsicum annuum L.) under the influence of varied potassium fertilization," Acta Scientiarum Polonorum-Hortorum Cultus, vol. 11, no. 4, pp. 3-15, 2012.

[16] J. Curry, M. Aluru, M. Mendoza, J. Nevarez, M. Melendrez, and M. A. O'Connell, "Transcripts for possible capsaicinoid biosynthetic genes are differentially accumulated in pungent and non-pungent Capsicum spp," Plant Science, vol. 148, no. 1, pp. 47-57, 1999.

[17] D. T. Clarkson and J. B. Hansonn, "The mineral nutrition of higher plants," Annual Review of Plant Physiology, vol. 31, pp. 239-298, 1980.

[18] F. Medina-Lara, I. Echevarría-Machado, R. Pacheco-Arjona, N. Ruiz-Lau, A. Guzmán-Antonio, and M. Martinez-Estevez, "Influence of nitrogen and potassium fertilization on fruiting and capsaicin content in habanero pepper (Capsicum chinense Jacq.)," HortScience, vol. 43, no. 5, pp. 1549-1554, 2008.

[19] C. D. Johnson and D. R. Decoteau, "Nitrogen and potassium fertility affects Jalapeno pepper plant growth, pod yield, and pungency," HortScience, vol. 31, no. 7, pp. 1119-1123, 1996.

[20] W. L. Scoville, "Note on capsicums," Journal of the American Pharmaceutical Association, vol. 1, no. 5, pp. 453-454, 1912.

[21] H. A. A. Gibbs and L. W. O. O'Garro, "Capsaicin content of West Indies hot pepper cultivars using colorimetric and chromatographic techniques," HortScience, vol. 39, no. 1, pp. 132-135, 2004.

[22] P. H. Todd, M. G. Bensinger, and T. Biftu, "Determination of pungency due to capsicum by gas-liquid chromatography," Journal of Food Science, vol. 42, no. 3, pp. 660-665, 1977.

[23] K. Iwai, T. Suzuki, H. Fujiwake, and S. Oka, "Simultaneous microdetermination of capsaicin and its four analogues by using high-performance liquid chromatography and gas chromatography-mass spectrometry," Journal of Chromatography A, vol. 172, no. 1, pp. 303-311, 1979.

[24] N. T. Nyberg, H. Baumann, and L. Kenne, "Application of solidphase extraction coupled to an NMR flow-probe in the analysis of HPLC fractions," Magnetic Resonance in Chemistry, vol. 39, pp. 236-240, 2001.

[25] S.-H. Choi, B.-S. Suh, E. Kozukue, N. Kozukue, C. E. Levin, and M. Friedman, "Analysis of the contents of pungent compounds in fresh Korean red peppers and in pepper-containing foods," Journal of Agricultural and Food Chemistry, vol. 54, no. 24, pp. 9024-9031, 2006.

[26] A. M. Krajewska, Isolation, identification and sensory evaluation of capsaicinoids [Ph.D. thesis], University of Georgia, Athens, Ga, USA, 1984.

[27] J. J. DiCecco, "Spectrophotometric difference method for determination of capsaicin," Journal Association of Official Analytical Chemistry, vol. 62, pp. 998-1000, 1979.
[28] D. A. Nikolaeva, "Spectrophotometric determination of capsaicin in peppers (Capsicum annuum L.)," Biokhim. Metody Analiza Plodov, Kishinev, pp. 99-102, 1984.

[29] C. B. Davis, C. E. Markey, M. A. Busch, and K. W. Busch, "Determination of capsaicinoids in habanero peppers by chemometric analysis of UV spectral data," Journal of Agricultural and Food Chemistry, vol. 55, no. 15, pp. 5925-5933, 2007.

[30] Instituto Nacional de Estadística y Geográfia (INEGI), Prontuario de Información geográfica municipal de los Estados Unidos Mexicanos, Edited by Francisco I. Madero, INEGI, Coahuila de Zaragoza, Mexico, 2009.

[31] C. Molina, A. Morales, and A. Márquez, Técnicas para el establecimiento y producción de chiltepín silvestre, bajo un sistema agroforestal en Sonora, México. Capsicum annuum L. var. glabriusculum (Dunal) Heiser \& Pickersgill, CONAFOR, ITVY, INIFAP, Jalisco, México, 2009.

[32] Z. A. Al Othman, Y. B. H. Ahmed, M. A. Habila, and A. A. Ghafar, "Determination of capsaicin and dihydrocapsaicin in Capsicum fruit samples using high performance liquid chromatography," Molecules, vol. 16, no. 10, pp. 8919-8929, 2011.

[33] M. Parrish, "Liquid chromatographic method of determining capsaicinoids in Capsicum and their extractives: colaborative study," Journal Association of Official Analytical Chemistry, vol. 79, pp. 738-745, 1996.

[34] K. Sanatombi and G. J. Sharma, "Capsaicin content and pungency of different Capsicum spp. cultivars," Notulae Botanicae Horti Agrobotanici Cluj-Napoca, vol. 36, pp. 89-90, 2008.

[35] M. Locatelli, G. Carlucci, S. Genovese, M. Curini, and F. Epifano, "Use of HPLC in the determination of the molar absorptivity of 4/-geranyloxyferulic acid and boropinic acid," Chromatographia, vol. 73, no. 9-10, pp. 889-896, 2011.

[36] T. Suzuki and K. Iwai, "Chapter 4 constituents of red pepper species: chemistry, biochemistry, pharmacology, and food science of the pungent principle of Capsicum species," The Alkaloids: Chemistry and Pharmacology, vol. 23, pp. 227-299, 1984.

[37] S. Kosuge, Y. Inagaki,, and M. Nishinura, "Studies on pungent principles of red pepper IV. Paper chromatography of pungent principles," Journal of the Agricultural Chemical Society of Japan, vol. 33, no. 11, pp. 915-918, 1959.

[38] B. Estrada, F. Pomar, J. Díaz, F. Merino, and M. A. Bernal, "Effects of mineral fertilizer supplementation on fruit development and pungency in Padron peppers," The Journal of Horticultural Science and Biotechnology, vol. 73, no. 4, pp. 493497, 1998.

[39] M. Monforte-González, A. Guzmán-Antonio, F. Uuh-Chim, and F. Vázquez-Flota, "Capsaicin accumulation is related to nitrate content in placentas of habanero peppers (Capsicum chinense Jacq.)," Journal of the Science of Food and Agriculture, vol. 90, no. 5, pp. 764-768, 2010.

[40] C. A. Edwards and I. Burrows, "The potential of earthworm composts as plant growth media," in Earthworms in Environmental and Waste Management, C. A. Neuhauser, Ed., pp. 211220, SPB Academic Publishing, The Hague, the Netherlands, 1988.

[41] J. J. Tewksbury, G. P. Nabhan, D. Norman, H. Suzán, J. Tuxill, and J. Donovan, "In situ conservation of wild chiles and their biotic associates," Conservation Biology, vol. 13, no. 1, pp. 98-107, 1999.

[42] N. Rodríguez Dimas, P. Cano Ríos, U. Figueroa Viramontes et al., "Tomato production in greenhouse using vermicompost as 
substrate," Revista Fitotecnia Mexicana, vol. 31, no. 3, pp. 265$272,2008$.

[43] A. Hernández, H. Castillo, D. Ojeda, A. Arras, J. López, and E. Sánchez, "Effect of vermicompost and compost on lettuce production," Chilean Journal of Agricultural Research, vol. 70, no. 4, pp. 583-589, 2010.

[44] P. Ramesh, M. Singh, and A. Subba Rao, "Organic farming: its relevance to the Indian context," Current Science, vol. 88, no. 4, pp. 561-568, 2005.

[45] N. Q. Arancon, C. A. Edwards, R. M. Atiyeh, and J. D. Metzger, "Effects of vermicomposts produced from food waste on the growth and yields of greenhouse peppers," Bioresource Technology, vol. 93, no. 2, pp. 139-144, 2004.

[46] S. T. López-Espinosa, A. Moreno-Reséndez, P. Cano Ríos, N. Rodríguez-Dimas, V. Robledo-Torres, and C. Márquez-Quiroz, "Organic fertilization: an alternative to produce jalapeño pepper under greenhouse conditions," Emirates Journal of Food and Agriculture, vol. 25, pp. 666-672, 2013.

[47] J. A. Barrera, M. S. Hernández, L. M. Melgarejo, O. Martínez, and J. P. Fernández-Trujillo, "Physiological behavior and quality traits during fruit growth and ripening of four Amazonic hot pepper accessions," Journal of the Science of Food and Agriculture, vol. 88, no. 5, pp. 847-857, 2008.

[48] E. Mueller-Seitz, C. Hiepler, and M. Petz, "Chili pepper fruits: content and pattern of capsaicinoids in single fruits of different ages," Journal of Agricultural and Food Chemistry, vol. 56, no. 24, pp. 12114-12121, 2008.

[49] B. Estrada, M. A. Bernal, J. Díaz, F. Pomar, and F. Merino, "Fruit development in Capsicum annuum: changes in capsaicin, lignin, free phenolics, and peroxidase patterns," Journal of Agricultural and Food Chemistry, vol. 48, no. 12, pp. 6234-6239, 2000.

[50] N. Deepa, C. Kaur, B. George, B. Singh, and H. C. Kapoor, "Antioxidant constituents in some sweet pepper (Capsicum annuum L.) genotypes during maturity," LWT: Food Science and Technology, vol. 40, no. 1, pp. 121-129, 2007.

[51] S. Hernández-Verdugo, R. G. Guevara-González, R. F. RiveraBustamante, and K. Oyama, "Screening wild plants of Capsicum annuum for resistance to pepper huasteco virus (PHV): presence of viral DNA and differentiation among populations," Euphytica, vol. 122, no. 1, pp. 31-36, 2001. 

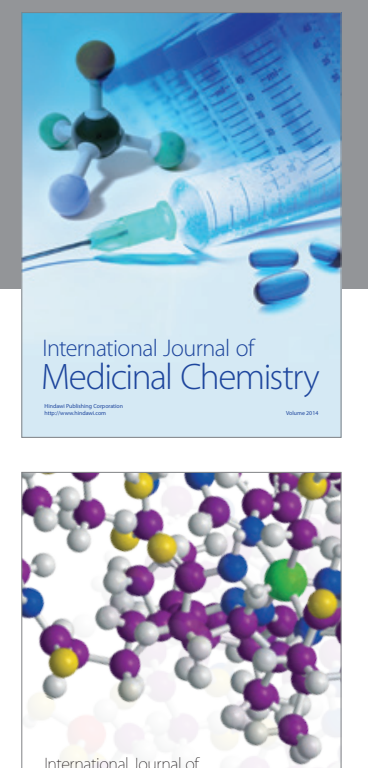

\section{Carbohydrate} Chemistry

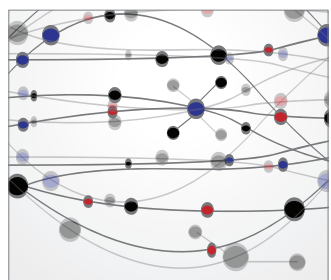

The Scientific World Journal
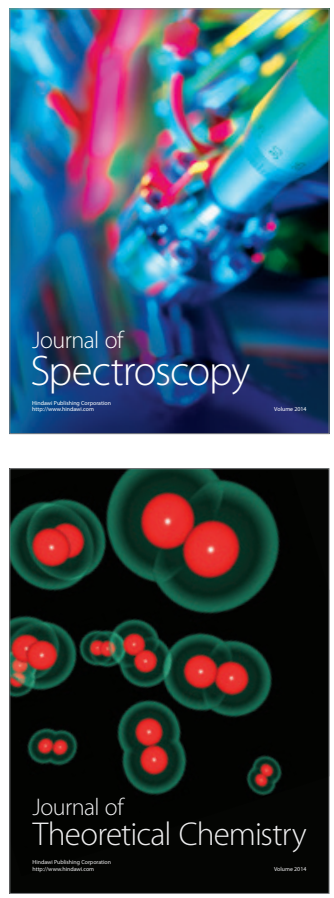
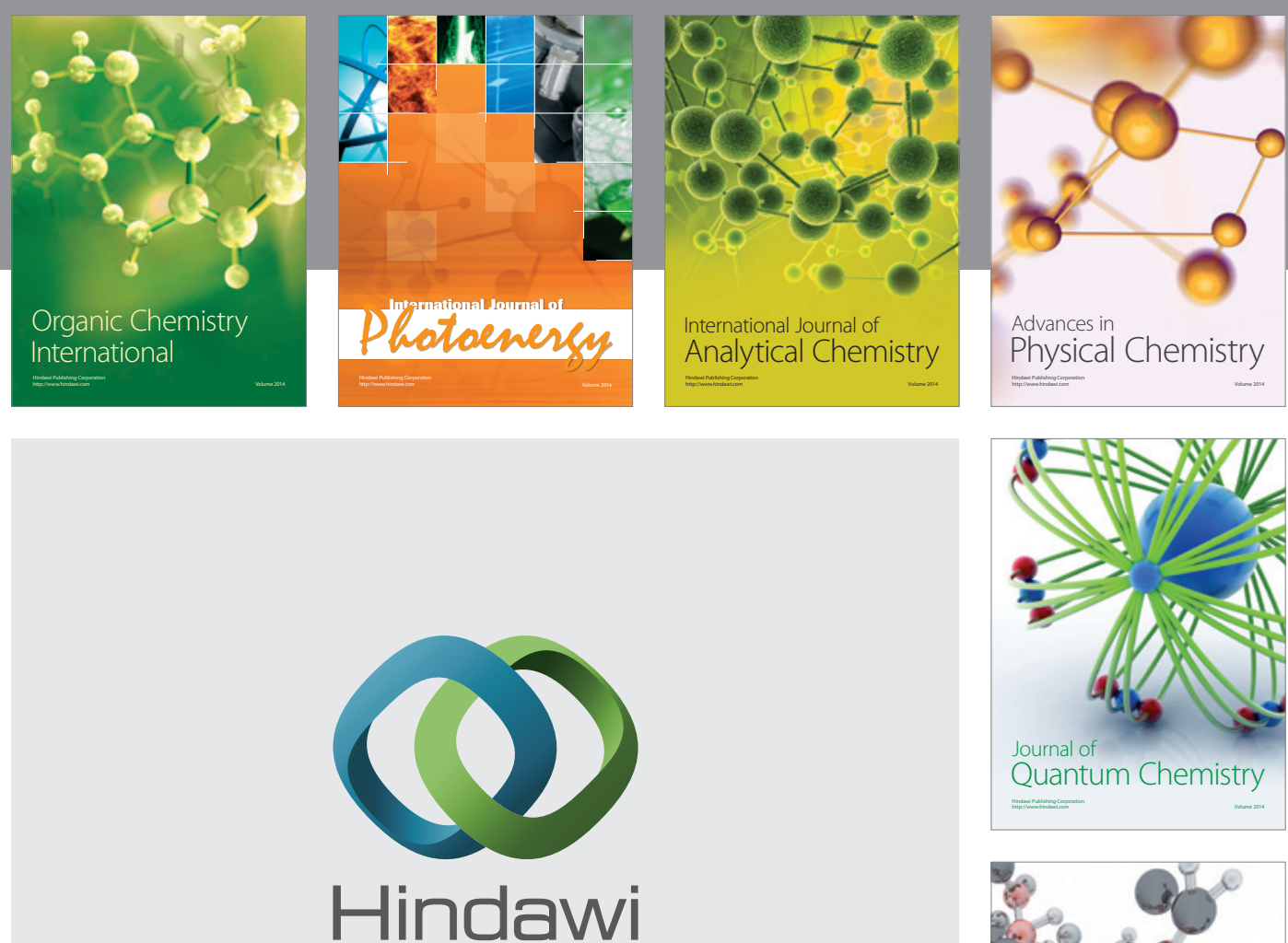

Submit your manuscripts at

http://www.hindawi.com

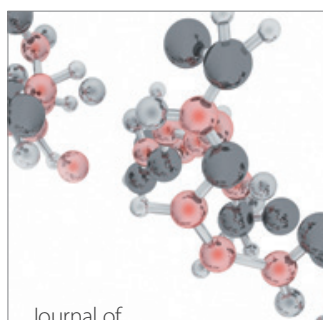

Analytical Methods

in Chemistry

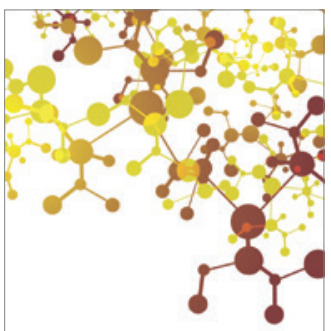

Journal of

Applied Chemistry

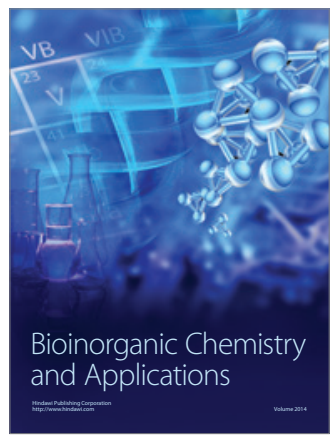

Inorganic Chemistry
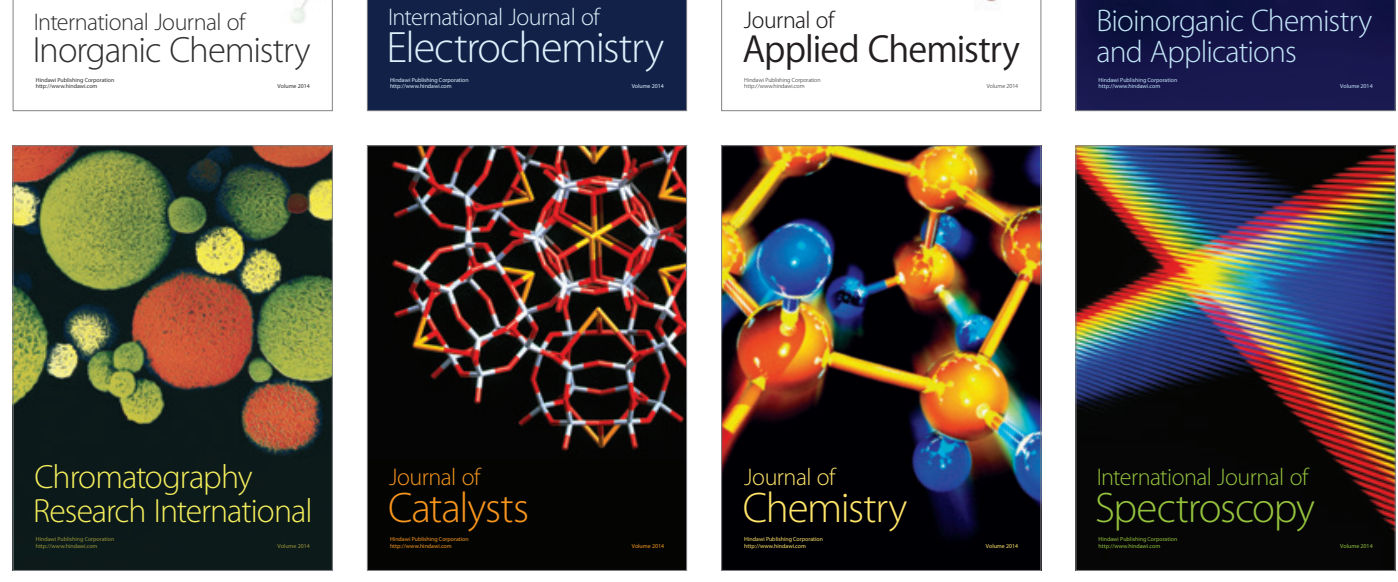